$\underline{\text { Article }}$

\title{
Maleic Anhydride Grafting on EPDM: Qualitative and Quantitative Determination
}

\author{
Guilherme M.O. Barra, Janaina S. Crespo, José R. Bertolino, \\ Valdir Soldi, and Alfredo T. Nunes Pires*
}

Laboratório de Materiais Poliméricos, Departamento de Química, Universidade Federal de Santa Catarina, 88040-900 Florianópolis - SC, Brazil

\begin{abstract}
Nos últimos anos tem sido estudada a modificação de polímeros com grupos funcionais específicos, com o objetivo de obter blendas compatíveis com propriedades macroscópicas desejáveis. Neste trabalho foi determinado a percentagem do enxerto do EPDM com anidrido maleico (AM), em solução, utilizando peróxido de benzoila como iniciador. As condições de enxerto foram estudadas em função do tempo de reação e da quantidade de anidrido maleico. Para a determinação quantitativa do AM enxertado na cadeia do EPDM foi utilizado o método de espectroscopia de infravermelho, sendo o procedimento discutido em detalhes.
\end{abstract}

Several attempts have been made to compatibilize immiscible blends by introducing suitablychosen polymer additives. This work studies the EPDM elastomer, chemically modified with maleic anhydride (MA), through reaction in solution of EPDM and MA, using dibenzoyl peroxide as an initiator. The best conditions for obtaining the maximum grafting were studied at different times and percentage weights of maleic anhydride. The evaluation of MA grafting onto EPDM was determined with multiple internal reflectance infrared spectroscopy as discussed in detail.

Keywords: EPDM, maleic anhydride, grafting

\section{Introduction}

The maleic anhydride (MA) modification of different kinds of rubbers is a useful way of compatibilizing immiscible polymer blends as well as improving interfacial adhesion in polymeric composites. Several factors can influence mechanical properties, such as the particle size and particle-size distribution of the dispersed phase, and the degree of interfacial adhesion between two phases. The adequate chemical structure of the compatibilized agent can reduce the interfacial energy between the phases and a finer dispersion can be obtained $^{1}$, improving its performance in terms of enhanced impact strength. For example, the modification of EPDM rubber with MA in a twin screw extrusion process has been described by Oostenbrink and Gaymans, in the presence or absence of bis(t-butyl peroxy isopropyl)benzene as an initiator $^{2}$. Xie et al. studied the maleation of EPDM in xylene solution using dibenzoyl peroxide as an initiator of the grafting reaction ${ }^{3}$. The knowledge of MA content in the rubber by covalent linking is important not only to evaluate its application but also to choose the best manner of grafting. Different techniques have been reported in the literature, such as gravimetry, titration of acid group, infrared spectroscopy, and so on. Each technique is limited with regard to its sensitivity and range of application. Infrared spectroscopy permits a series of variations in the form of acquiring data. Multiple reflectance infrared spectroscopy has high sensitivity and the ability to analyse insoluble and opaque polymers without drastic thermal or physical treatment, in contrast to the usual transmission infrared spectroscopy which is only capable of analysing transparent films. Studies reported in the literature ${ }^{4}$ using Diffuse Reflectance FTIR discuss the complicated procedures for quantitative analyses, due to nonproportional relationships between concentration and pseudo-absorbance. In the present work, we used Multiple Reflectance FTIR in order to simplify the method of quantitative determination of the percentage of maleic anhydride grafting in the EPDM chain.

\section{Experimental}

\section{Material}

The ethylene-propylene-ethylene-diene monomer (EPDM) can be found as a commercial product with differ- 
ent comonomers and resulting terpolymers. In this work, we used EPDM with an ethylidene norbornene content of $1.7 \%$, as shown below, kindly supplied by Nitriflex. A sample of EPDM-g-MA (Uniroyal Chemical) with $0.5 \%$ of maleic anhydride indicated by the supplier, was used to ratify the present method.<smiles>CC=C1CC2CC(CC(C)CCCI)C(C1)C2P</smiles>

Maleic anhydride (Merck) and dibenzoyl peroxide (VETEC) were recrystallized from chloroform and ethanol respectively, and were employed according to standard procedures. The EPDM was used as received without any additional purification.

\section{Techniques}

Small pieces of EPDM elastomer were added to chlorobenzene and heated while stirring. When the temperature reached $80^{\circ} \mathrm{C}$, solutions of maleic anhydride and dibenzoyl peroxide in chlorobenzene were added to the vessel and reacted for different times at this temperature. Then, the graft EPDM-g-MA was precipitated in methanol and it was washed several times with acetone, maintaining it under vacuum at $40{ }^{\circ} \mathrm{C}$ for $24 \mathrm{~h}$.

The physical mixtures (EPDM/MA) were prepared by dissolving undiluted components in chloroform by stirring and maintaining them at room temperature until complete solvent evaporation.

FTIR spectra of EPDM, EPDM-g-MA and EPDM/MA films were carried out in a 16 PC Perkin Elmer spectrophotometer, equipped with a multiple reflectance accessory, resolution $4 \mathrm{~cm}^{-1}$, and performing 20 scans. The films were supported on KRS-5 crystal. In the case of the presence of close bands in the analysis, the spectra can be fitted to evaluate the real contribution of each one, using Origin 4.1 software with Gaussian or Lorentzian bases. The same band height relations were obtained for both functions.

\section{Results and Discussion}

Initially, we describe the procedure for determining the extent of grafting of maleic anhydride on to the backbone of the EPDM macromolecule by FTIR spectrum. Figure 1 shows the multiple internal reflectance infrared spectrum of EPDM and EPDM-g-MA, where the inside numbers indicate the assignment according to absorption group as described in Table 1 . We may observe the $\mathrm{C}=\mathrm{O}$ stretching band of maleic anhydride at 1856 (low intensity) and 1780 $\mathrm{cm}^{-1}$ (medium intensity) ${ }^{5,6}$, and a band at $1707 \mathrm{~cm}^{-1}$ due to the $\mathrm{C}=\mathrm{O}$ stretching group of hydrolised MA in EPDM-g$\mathrm{MA}^{6}$. The band at $922 \mathrm{~cm}^{-1}$ is due to angular deformation outside the plane of the $\mathrm{OH}$ hydrogen bonding, which is indicative of MA incorporated in the EPDM rubber. However, the maleic anhydride is partially converted to the acid

Table 1. Characteristic infrared bands of the EPDM and EPDM-g-MA spectrum.

\begin{tabular}{lllll}
\hline band number & $\begin{array}{l}\text { band intensity wave } \\
\text { number }\end{array}$ & $\mathrm{cm}^{-1}$ & absorption & assignment \\
\hline EPDM & strong & & & stretching vibration \\
1 and 2 & medium & 2925,2850 & $\mathrm{CH}$ & stretching vibration \\
3 & strong & 1630 & $\mathrm{C}=\mathrm{C}$ & angular deformation \\
4 & medium & 1460 & $\mathrm{CH}_{2}$ & angular deformation \\
5 & medium & 1375 & $\mathrm{CH}_{3}$ & angular deformation \\
6 & 720 & $\mathrm{CH}_{2}$ & stretching vibration \\
EPDM-g-MA & strong & 2925,2850 & & asymmetric stretching \\
1 and 2 & low & 1856 & $\mathrm{CH}$ & symmetric stretching \\
3 & medium & 1780 & $\mathrm{C}=\mathrm{O}$ & $\mathrm{C}=\mathrm{O}$ \\
4 & low & 1707 & $\mathrm{C}=\mathrm{O}$ & symmetric stretching* \\
5 & strong & 1460 & $\mathrm{CH}$ & angular deformation \\
6 & medium & 1375 & $\mathrm{CH}_{3}$ & angular deformation \\
7 & medium & 922 & $\mathrm{OH}$ & angular deformation \\
\hline
\end{tabular}

* due to acid form. 
form under room conditions, and the control of probable mixture of the two extreme forms is very difficult because it is a function of many variables. In order to avoid quantities in both forms, maleic anhydride was totally converted to maleic acid, maintaining it above a water vapour for $4 \mathrm{~h}$, as shown in Fig. 2. We may observe the rise of a band at $1707 \mathrm{~cm}^{-1}$ and the disappearance of bands at 1856 and 1780 $\mathrm{cm}^{-1}$. This process is reversible, if this sample is heated at $100{ }^{\circ} \mathrm{C}$ under vacuum for $24 \mathrm{~h}^{7}$. Figure 3 shows the infrared spectrum of maleic anhydride and maleic acid, with only one clear band at $1707 \mathrm{~cm}^{-1}$ in the range of 1690 and $1890 \mathrm{~cm}^{-1}$.

No shifts are observed in the characteristic bands of maleic anhydride grafting or in the physical mixture with EPDM, indicating no change in the group vibration according to whether the components are covalently linked or not. This observation can facilitate the obtention of the calibration curve for the physical mixture. The calibration curve was prepared from the spectrum of physical mixtures of different compositions of maleic acid and EPDM, using the

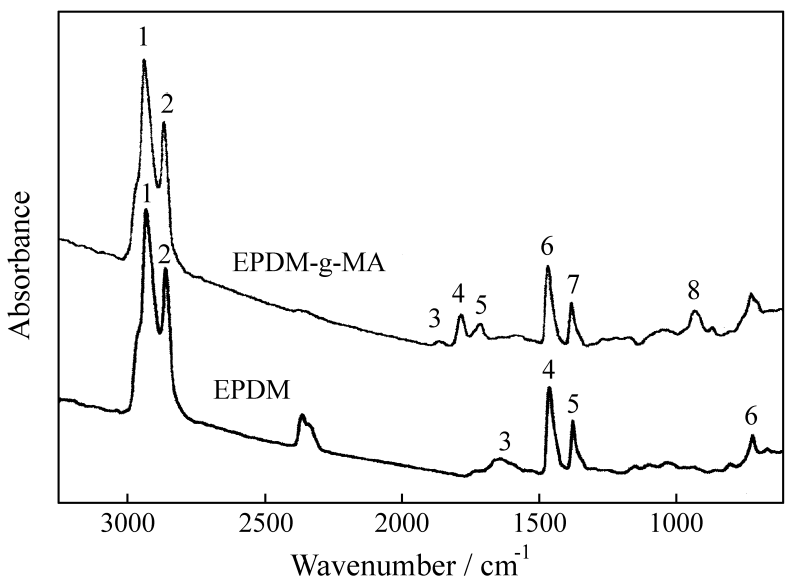

Figure 1. Infrared multiple internal reflectance spectrum of EPDM and EPDM-g-MA.

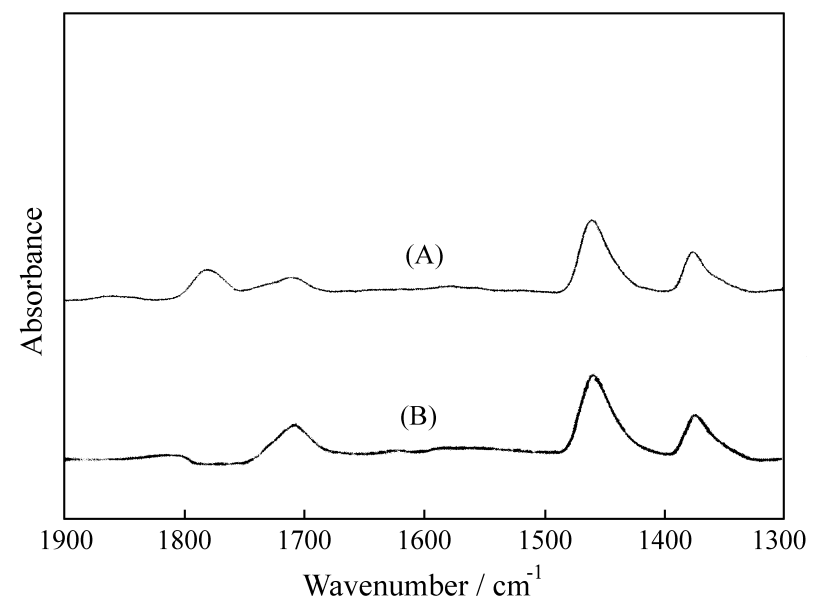

Figure 2. Spectrum of maleic anhydride (A) or maleic (B) acid grafting in EPDM rubber. ratio from band heights at 1707 (maleic acid) and $1460 \mathrm{~cm}^{-1}$ (EPDM). These two characteristic bands of each component permit the use of infrared as a quantitative method. However, it is necessary to obtain the calibration curve for the same EPDM, due to a possibility of variable content of ethylene and propylene in the main elastomer chain. The fitting of the spectrum bands was necessary in order to evaluate the ability of different mixtures to abolish the contribution of the band at $1430 \mathrm{~cm}^{-1}$ in the total absorbance and also to avoid intrinsic error. The Lorenz and Gauss mathematical functions give comparable band heights which are different, rising when the MA concentration increases without curve fit. This behavior is expected because the rise of maleic acid increases the band overlay. Figure 4 shows a typical spectrum of EPDM/maleic acid physical mixture with and without fit. Figure 5 shows the band ratio, $\mathrm{h}_{1707} / \mathrm{h}_{1460}$, as a function of different maleic acid concentrations. The linear relation is observed when the fit is used, in contrast to results without fit for the upper concentration of $4 \%$. The grafting of maleic acid on EPDM can be estimated by the curve shown in Fig. 5 as $1.9 \%$ weight or $1.9 \times 10^{-4} \mathrm{~mol} / \mathrm{g}$.

The determination of grafting maleic anhydride grade was made on a commercial sample of EPDM-g-MA, after being changed into the maleic acid form. The $\mathrm{h}_{1707} / \mathrm{h}_{1460}$ ratio was determined in the infrared spectrum (Fig. 6) as equal to 0.07 , and the grafting maleic anhydride was obtained from the graph in Fig. 5 as equal to $0.6 \%$. This value agrees with that given by the company supplying the product.

There is no effect of maleic anhydride concentration on the degree of maleic anhydride grafting of EPDM (1.7\% of diene) rubber, using $2.0 \mathrm{~g}$ of EPDM and $0.15 \mathrm{~g}$ of dibenzoyl peroxide, at $80{ }^{\circ} \mathrm{C}$ for $3 \mathrm{~h}$. The conversion reached a maximum value at $1.9 \%$ weight for all MA ranges studied. This value corresponds to at least $2.9 \times 10^{-3} \mathrm{~g}$ or $2.9 \times 10^{-4}$ mol of MA, indicating an equimolar relation with the diene

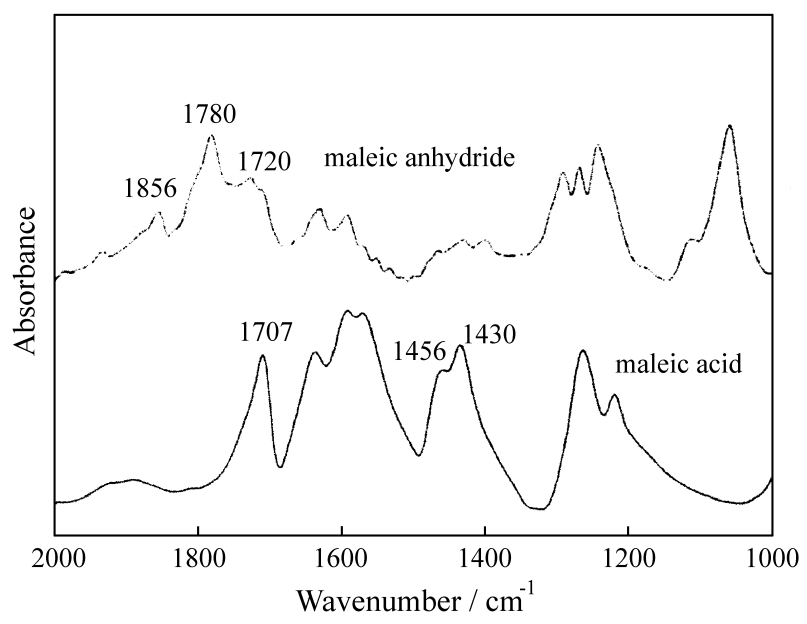

Figure 3. Infrared spectrum of maleic anhydride and maleic acid. 


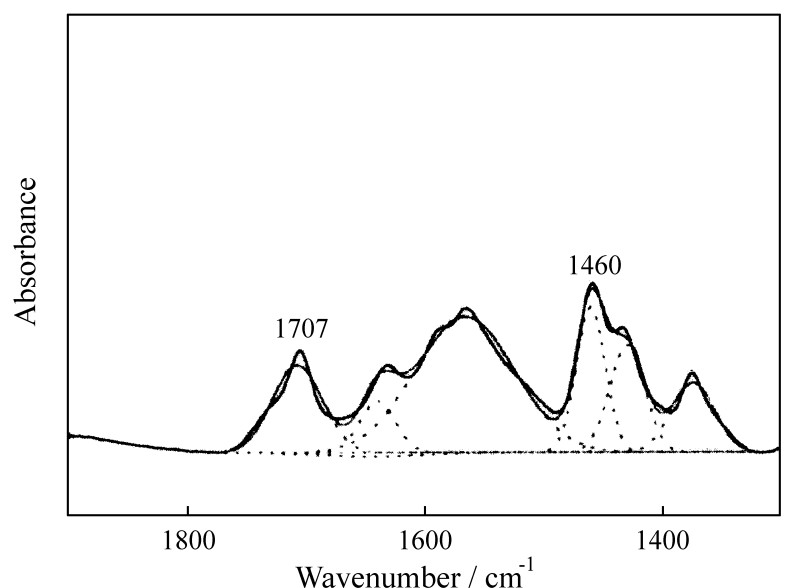

Figure 4. EPDM/maleic acid physical mixture spectrum. The dashed line indicates the bands after fitting.

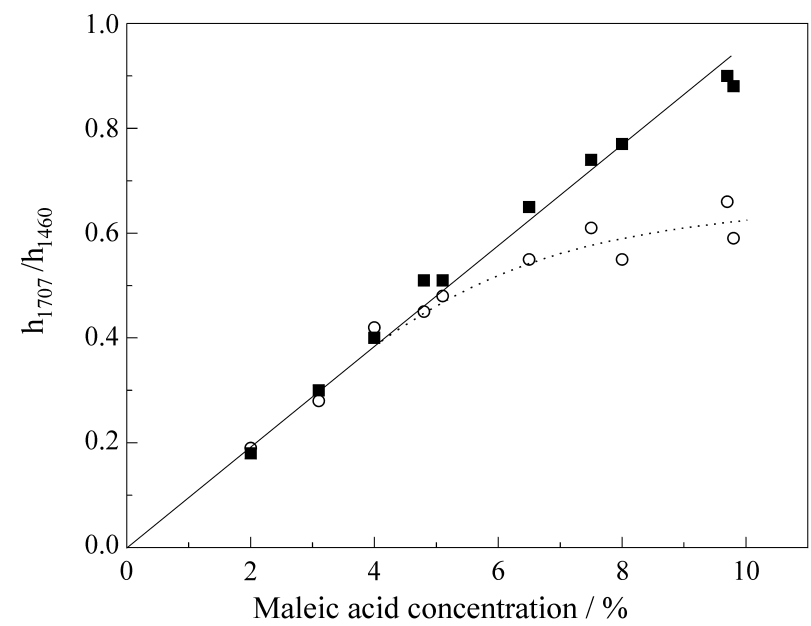

Figure 5. Calibration curve of EPDM/ maleic acid physical mixture using ratio height band $(\square)$ with fit and $(\mathrm{O})$ without fit.

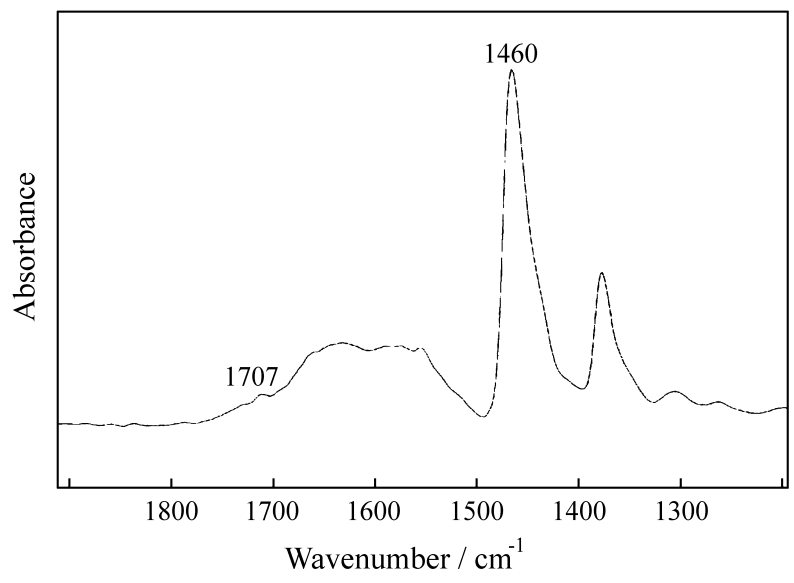

Figure 6. Infrared multiple internal reflectance spectrum of commercial EPDM-g-MA, supplied as $0.5 \%$ of maleic anhydride.

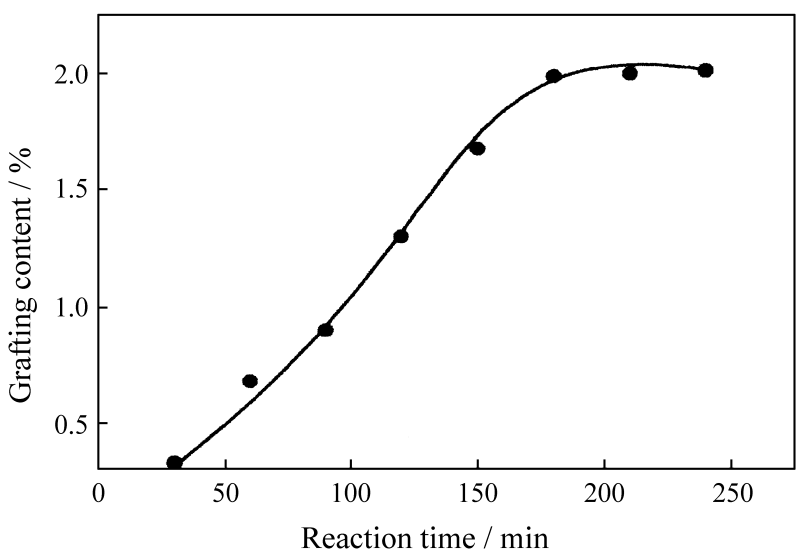

Figure 7. Reaction time versus grafting content of MA, at $0.15 \mathrm{~g}$ dibenzoyl peroxide, $2.0 \mathrm{~g}$ of EPDM and $2.9 \times 10^{-3} \mathrm{~g}$ maleic anhydride, at $80^{\circ} \mathrm{C}$.

percentage in EPDM monomeric units. The maleic anhydride grafting, at $80{ }^{\circ} \mathrm{C}$ and $0.15 \mathrm{~g}$ of dibenzoyl peroxide, $2.9 \times 10^{-3} \mathrm{~g}$ maleic anhydride and $2.0 \mathrm{~g}$ of EPDM, rises to a maximum after $3 \mathrm{~h}$ of reaction (Fig. 7). The conditions described above were used in all experiments to evaluate the MA grafting content.

\section{Conclusion}

The presence of maleic anhydride grafting on EPDM was made evident by infrared analysis, and it was possible to detect the carboxyl group band of maleic anhydride at 1856 and $1780 \mathrm{~cm}^{-1}$. The infrared spectrum with band fit minimizes the error in determining the content of maleic acid and it is a simple and useful method for evaluating the percentage of grafting, using the ratio from band heights of the infrared spectrum at specific wave numbers corresponding to each component in the mixture.

\section{References}

1. Newman, S. In Rubber modification of plastics, Paul, D.R.; Newman, S., eds., Polymer blend. New York: Academic, 1978, 2, 63.

2. Oostenbrink, A.J.; Gaymans, R.J. Polymer 1992, 33(14), 3086.

3. Xie, H.Q.; Feng, D.S.; Guo, J.S. Journal of Applied Polymer Science 1997, 64(2), 329.

4. Coutinho, F.M.B.; Ferreira, M.I.P. Polymer Testing 1994, 13, 25.

5. Wu, C.H.; Su, A.C. Polymer Engineering and Science 1990, 31, 1975.

6. Cimmino, S. et al. Polymer Engineering and Science 1985, 25, 193.

7. Lanzetta, L. et al. Polymer Bolletin 1989, 32, 603. 